\title{
Social enterprise evaluation: Implications for tourism development
}

\author{
Marcella Daye, Northampton Business School, University of Northampton, UK \\ marcella.daye@northampton.ac.uk \\ and \\ Kawal Gill, Sri Guru Gobind Singh College of Commerce, University of Delhi \\ drkawallgill@gmail.com
}

\begin{abstract}
The evaluation of social enterprise projects has focused mainly on devising effective performance measurement methods and processes to justify the investment of resources and time committed to such activities. With increasing demands for accountability, effectiveness, evidence of return on investment and value-added results, evaluation activities have been driven by imperatives of objectivity in assessments and the development of tools that monetize the social outcomes and impacts of social enterprise projects. These traditional approaches to evaluation have also been widely adapted in tourism based social enterprises that seek to attain goals of poverty alleviation, empowerment of local communities, and improved livelihoods for those marginalized from mainstream tourism economic activities. This chapter argues that traditional approaches to evaluation may be limited in supporting social entrepreneurship projects with development objectives of empowerment and societal change. It is proposed that social enterprise projects involving community participation may be better positioned to achieve their developmental objectives by incorporating more of the principles of Participatory Evaluation (PE) and Empowerment Evaluation (EE) in the quest to harness the economic prowess of tourism for human development.
\end{abstract}

\subsubsection{Introduction}

The conventional mission of social enterprise or entrepreneurship projects to provide solutions to social problems and unmet needs that are unlikely to be addressed by market forces, inherently invokes the expectation of effective results and ameliorative outcomes for the wider society. This solution and innovation orientation predisposes social enterprise activities as offering some remedy to challenging societal difficulties. Ideally, successful social enterprise projects are able to clearly demonstrate that their activities and interventions relate directly to some beneficial change and desirable social impacts. The bottom line is therefore for the social enterprise to show that no other organization is also responsible for the outcomes; and that they are counterfactual, that is, would not have occurred anyway without the intervention (Hall \& Arvidson, 2014).

Nevertheless, the evaluation of social enterprise impacts and effectiveness is by no means standardized and the landscape is cluttered with myriad methods and approaches. Normative approaches to the evaluation of social enterprises stress the importance of performance measurements and accountability to justify the time and resources engaged in undertaking the project. It is notable that the principles of objectivity with the role of the evaluator standing outside the activity or intervention are highly regarded among donor 
agencies and governments as a neutral and logical basis to measure the outcomes of social entrepreneurship (Chouinard, 2013). A premier example of objective evaluation is the application of Randomized Controlled Trials (RCTs) that has been advocated as a gold standard of evaluating impacts by comparing a beneficiary group with a controlled group, where there is no intervention. While RCTs offer a clinical approach to evaluation, it has been charged for reducing performance measurement to 'some unitary stable and objectively real' state when such issues are usually 'multi-faceted, problematic, ambiguous and contested'(Paton, 2003).

In adopting a more constructivist approach to performance measurement, holistic methods of social enterprise evaluation have gained currency epitomized in the Triple Bottom Line (TBL) approach of Profit, People and Planet, also known as a blended value method that incorporates financial, social and environmental accountability in assessments. However, such methods tend to focus on the monetization of social impacts as exemplified in the Social Return on Investment (SROI) tool. As a method, SROI measures the inputs relating to the resources invested in activities, the outputs in terms of goods and services achieved based on the activities; the outcomes that assess the benefits gained for beneficiaries; as well as the impacts with regard to the consequences for the society at large (Bagnoli \& Megali, 2011). While the main charge against SROI is a failure to valorize benefits delivered to clients such as confidence, independence and dignity, it also may create a context of mission drift or 'mission measurement paradox' where growth in numbers of beneficiaries or profits is equated with successful impacts rather than the overarching mission of social change and empowerment (Hadad \& Gauca, 2014).

As argued by (Nichols, 2002), if ultimately the perspectives of those affected by social enterprise activities determine success, then the case may be made for the role of participatory methods which engage beneficiaries in the evaluation process. As a bottom-up approach, participatory evaluation (PE) seeks to transfer power to beneficiaries that equip them to make meaningful decisions to improve their lives. This method advocates the involvement of key stakeholders from the incipient stage through to completion of the project in order to ensure that the evaluation results are utilized and applied to individual and organizational learning. At its highest level of expression, this process is termed Empowerment Evaluation (EE) where there is evidence of actual power shifts that enable marginalized groups to carry out evaluation work and to 'mainstream such activities into programming' (Miller \& Campbell, 2006a). However, participatory methods seem to have more credence as an engagement and mobilization tool, rather than an evaluation method. The main reasons are that the implementation of participatory evaluation tends to be stymied by high training costs, extensive time and also limited utilization of results. Furthermore, participatory and empowerment models of evaluation have yet to be universally recognized as rigorous and providing value for money (Miller \& Campbell, 2006b; Smits \& Champagne, 2008a).

In this chapter the theoretical underpinnings of a range of evaluation approaches and methods are appraised in order to clarify their applicability and suitability in the social enterprise context. All evaluation tools are informed by some epistemological and theoretical principle that guides the data collection and the assessment of the causal links between the programme design and the eventual outcomes. Often times in practice, there may be 
differences of philosophical persuasions among stakeholders involved in the social enterprise projects as to which evaluation methods are most suitable to assess the results. In this regard, stakeholder collaboration in the design and implementation of evaluation have been advocated in order to ensure the utilization of evaluations that ultimately contribute to organizational and general learning of the critical success factors of social enterprise projects (Liket, Rey-Garcia, \& Maas, 2014); White, 2009). This chapter then concludes with an overview of social enterprise evaluation in the tourism sector. The discussion focuses primarily on development projects, namely, community based tourism enterprises (CBTEs) that are predominantly modelled on the social enterprise ideal to achieve societal change and people empowerment. The role of empowerment evaluation in specifically targeting the needs of women through social enterprise projects is also discussed (Fotheringham \& Saunders, 2014).

\subsubsection{Performance Management for Social Enterprise}

The growth in popularity, prominence and acceptance of social entrepreneurship as a business innovation model on a global level has resulted in increasing scrutiny and interrogation of its claims as an approach to redress social problems (Hadad \& Gauca, 2014). With the landscape increasingly populated by social enterprise initiatives, the rationale for performance management is therefore an imperative in the allocation of resources and the quest to determine whether social enterprise projects effectively provide a competitive advantage over traditional producers and service providers in the public and private sectors. Performance evaluation therefore seeks to provide the mechanism to winnow the chaff of marketing and public relations claims of the success of social enterprise interventions from the realities of the specific changes that have been accrued to the society in their aftermath. The basic premise of social enterprise performance management in the evaluation process is to provide incontrovertible proof that the outcomes are directly attributable to the intervention thereby establishing what is called 'pragmatic legitimacy' (Parenson, 2011).

In practice however, while stakeholders may all agree on the need to demonstrate the pragmatic legitimacy and the efficacy of the project, it is unlikely that there will be unanimity on how this evaluation process should be designed and implemented. According to Behn, (2003), there are mainly eight purposes for the employment of the evaluation process by managers. These purposes have been identified as to control, budget, celebrate, motivate, promote, evaluate, learn and improve. While these are by no means mutually exclusive, they also reflect the varying motivations with which stakeholders are likely to approach the evaluation process that may also set the stage for the seeds of discord and conflict among stakeholders on the priorities for measurement, what type of data should be collected and how the design process should be implemented. Liket et al (2014:183) report on a case study where a funder and a non-profit enterprise were not able to agree on an evaluation process for a project as the funder preferred an outcomes mapping method, while the non-profit agency managers advocated a SROI approach. The impasse was eventually resolved when the two parties were enabled in a facilitation process to see the interrelationships between the various approaches to their preferred evaluation methods, and were able to establish a 'neutral ground' beyond a specific methodological conviction. According to Liket et al (2014:184), 
there may be the need for 'inherent trade-offs' in the selection of the evaluation methods so that the process is appropriate for the project context and also satisfies the requirements of all the stakeholders.

The emphasis on the adoption of a 'best fit' approach in selection of evaluation tools promotes a more plural orientation towards performance measurement in social enterprise. This has also fostered the proliferation of methods that are daily emerging in the field. But there are distinctive epistemological fields within which the diverse range of evaluation methods and tools may be categorized. Furthermore, various methods have been designed to address a specific context issue or have evolved and adapted over time as learning and new knowledge have been utilized. Nevertheless, the fundamental basis for the selection of the evaluation method for a social enterprise project is the recognition of its philosophical claims as well as the mode of implementation. As such, a review of a selection of various methods is undertaken in this chapter to highlight the distinctions between the various types and models that now clutter the evaluation field. Firstly, the case for positivist approaches is discussed with a review of selected methods and practices that define the field. This is followed by an overview of constructivist methodologies with a discussion of the main advantages and limitations of the implementation of these theoretical models in practice.

Within evaluation research, some differentiation is made between methods that make claims of rigor on the basis of being impartial and objective. White (2009:282) argues that quantitative methods are paramount and should be more widely applied in evaluation of developmental work as they provide the solid empirical basis to explain social impacts. Rooted in the positivist epistemological tradition, these methods aim to pursue the gathering of facts that are deemed to be measurable and seemingly uncontested. Such methods are mostly employed when the main purposes of the evaluation is to control, budget and also evaluate. Consequently methods that enable the demonstration of institutional coherence and also financial profitability fall within this tradition. When the objective is to demarcate the efficacy of social enterprise activities, the focus is likely to be on addressing the counterfactual, and in such cases, methods that employ experimental and quasi-experimental design featuring control groups are usually preferred. The measurement of outcomes according to eternal benchmarks, the utilization of panel data to test and verify results, and survey questionnaires are usually chosen as tools that attest to the rigor of the evaluation process. Generally positivist evaluation methods tend to be widely advocated by national governments and funding bodies as the preferred tool for accountability and stewardship of funding to SEs. Philosophically they subscribe to a managerial orientation of evaluation that is top-down and technocratic, where the evaluator is positioned as external to the project, and is therefore able to conduct an impartial, unbiased assessment of the intervention, thereby providing what is accepted by donor agencies as legitimate knowledge (Chouinard, 2013).

\section{The gold standard of evaluation - Random Controlled Trials (RCT) Adapted from its} primary usage in clinical trials, RCTs have been deemed as the gold standard of evaluation tools for its rigor, objectivity and the elimination of self-selection bias in the assessment process (Hall \& Arvidson, 2014); White, 2013). As a positivist, experimental method, RCT sets out to prove causality by comparing a control group that has not been subjected to the intervention, with one that was involved in the project. The operationalization of RCTs 
requires strict adherence to randomized selection of participants and also to ensure that there are no other factors outside the intervention that may have influenced the evaluation. This primary focus in attributing the main cause of change to the external intervention without factoring in possible contamination of the results by individual motives and actions has been pinpointed as a limitation of RCTs. In that regard, it is argued that while RCTs may demonstrate causality, it does not really provide deeper understandings on why the changes may have occurred. Furthermore, the stringent requirements for randomized selections and high level of skills required to undertake this kind of evaluation have also been cited as some of the main hindrances in applying RCT as a practical and appropriate method for SE evaluation. But for Hall \& Arvidson (2014: 152), even more troubling, is the notion of withholding a possible beneficial treatment or intervention to the members of the control group particularly in the context where there could be positive individual and societal change for the participants. White (2013) counters however, that in practice, it is not the case that control groups are offered no treatment in RCTs, instead they are often provided with alternative support and treatments that are distinct from the external intervention under examination. In defense of RCT, White (2013) contends further, that RCTs are worth the investment of time and money as they provide the proof of results and in so doing are much more ethical and prudent than scaling up interventions that are costly without the clear evidence that they do in fact work.

The role of financial and accounting reporting In spite of their general altruistic motivations, social enterprises have been predominantly governed by the prevailing managerial ethos that requires monitoring of activities with a careful eye on controlling costs to ensure that expenditure is kept within the budget (Bagnoli \& Megali, 2011). By demonstrating a financial profit, there is the obvious indicator of successful engagement with the market resulting in the attendant rewards of income generation and profits (Parenson, 2011). But the important distinction between social enterprises and traditional businesses, is the ability of social enterprises to demonstrate that their operations are not only financially sound, but also achieves the social aims set out in mission statements. Accordingly, social entrepreneurs prioritize the notion of social value and welfare creation which is the goal for the business beyond the economic value that is achieved. Nevertheless, it is generally accepted that the pretext for achieving social value is on the basis that the enterprise is income earning, self-sufficient and self-sustaining (Hadad \& Gauca, 2014). This duality of income generation and social welfare outcomes represents a hybrid value chain business model that is similar to a public sector commitment to the common good, and private sector principles of efficiency and financial stewardship. Therefore for most social enterprises, questions of efficiency and profitability are usually answered by instituting a financial accounting system to ensure internal control of costs, and also to provide accountability to funders and to meet standards of national and international legal funding compliance (Bagnoli \& Megali, 2011). But performance management is generally not reducible to the establishment of a financial accounting reporting system. The measurement of the performance of social enterprises also usually includes some notion of social accounting that provides a quantitative and qualitative summary of the beneficial social outcomes and impacts on the wider community (Hadad \& Gauca, 2014). 
Essentially, the rationale for performance management is to clearly demonstrate that the proposed interventions and actions of the social enterprise have some alignment with associated outcomes, and furthermore have been effective in the amelioration of the problem that was initially targeted. So the evaluation process is rooted in the fundamental principle of the logic model or logical framework that demonstrates how the resources that provide the Inputs relate to the Activities undertaken, that leads to direct Outputs, resulting in the Outcomes that have an extended Impact on the community (Hadad \& Gauca, 2014; Liket et al., 2014). But performance management may become hazardous in accurately measuring the results at the level of outcomes and impacts. Hall and Arvidson( 2014:143) point out that it is relatively straightforward to identify and monitor the inputs and outputs defined as hard indicators which are tangible. But the outcomes and impacts or soft indicators of a project are intangible and therefore more difficult to capture and measure. Soft indicators such as skills and competencies; dignity and self-worth; community pride and cohesion may emerge as unintended results from a project, that are oftentimes not measured and hence not valued. In such cases, positivist methods such as RCTs may not be effective in identifying the unintended impacts.

Another major challenge for the implementation of performance measurement is to demonstrate the validity of the process in ensuring that the data collected do in fact relate to and measure the indicators or constructs relating to outcomes and impacts. This involves some consideration of data selection and design so that they are clearly aligned with the outcomes and impacts of the project. White (2009: 274) advocates a theory based impact evaluation (TBIE) approach that maps out the casual link between inputs and outputs within an overarching programme theory that indicates how the proposed change may be only attributable to the intervention. White (2009:276) also contends however, that TBIE in evaluation is dynamic, involving an iterative process of continuous testing of the assumptions of the causal links between inputs and outputs of the programme represented in the logical framework (log frame) plan.

Social impact accounting - SORI Following on the principles of financial reporting, SEs have been at risk in assuming that financial profits or economic growth may also be used to demonstrate social value. The application of social impact accounting methods therefore seek to redress this jeopardy by taking into account the triple bottom line also known as the blended value approach that combine social, financial and environmental indicators (Hadad \& Gauca, 2014). The intent of social accounting methods is to monetize outcomes based on the application of financial proxies that account for the value of the social impacts ( Hall \& Arvidson, 2014). As an exemplar of social impact accounting methods, the Social Return on Investment (SROI) model popularized by the New Economic Foundation (NEF) and widely used across third sector organizations, has been extensively employed to evaluate the social outcomes of an organization's activities. According to (Pathak \& Dattani, 2014), SROI is comprised of 'six stages involving the identification of key stakeholders, mapping outcomes, evidencing outcomes and establishing impact, calculating the SROI and reporting, then using and embedding the report'. As a variant of Cost Benefit Analysis, SROI is considered as the foremost framework to measure value beyond financial returns to include the social, environmental and economic costs and benefits of SE activities. Hall \& Arvidson (2014:144) 
maintain that the advantage of SROI is that while it produces 'a quantitative monetary ratio of value' it also garners qualitative data from various stakeholders in order to identify the benefits and limitations of the intervention which is also included in the evaluation. In this regard, SROI is able to extend the evaluation beyond the outcomes that were earmarked as the goal of the intervention, to also include unintended benefits or outcomes for measurement, so that the 'story of how change is being created is told' through the evaluation exercise (Hall \& Arvidson, 2014).

By incorporating the views of multiple stakeholders in the evaluation process, SORI assists in the identification of the range of benefits of a project as well as the 'wider economic value and social returns' (Hadad \& Gauca, 2014). One of the main criticisms however of SROI, is the extent to which suitable financial proxies to measure social value may be identified. Other critiques include the limitation of the method in seeking to accomplish too many strategic objectives concurrently, as well as ethical issues on the equity of the process of stakeholder consultation (Hall \& Arvidson, 2014; Pathak \& Pathik, 2014). But the main contention against SORI is the charge of the prohibitive costs of operationalization, and that is often seen as a burden to managers and participants as well as a discrete activity outside of the main project work. These problems associated with SROI in many instances undermine and hinder the important daily schedules that must be undertaken for the success of the project.

The role of programmatic evaluation With the popularization of social accounting methods, performance management models are increasingly characterized by a quest for more holistic evaluation methods that incorporate financial and accounting reporting as well as social effectiveness measurement while providing institutional control and coherency between activities and outcomes. This is in recognition of the need to embed and integrate the evaluation process in the design and operations of the social enterprise. In this context, evaluation is not a stand-alone procedure or phase, but is implicated in the day to day management and execution of the project. Such approaches therefore prioritize the practical steps and actions related to impact assessment. According to (McLoughlin et al., 2009), the Practical Quality Assurance System method developed primarily for the third sector, is relevant for SEs as it provides a quality assurance mechanism of control for the organization. Similarly, the 'prove and improve' model developed by the NEF provides a practical 'DIY online impact measurement tool' that gives guidance for stakeholder analysis, impact mapping and indicator development.

While these methods provide the basis for integrating evaluation in the overall programme theory, yet the main limitation of these approaches are that they are still quite technical and require some level of expertise to implement that may be a challenge for inexperienced social enterprise managers (McLoughlin et al, 2009:158). In order to address this skills deficit and to equip SE managers to integrate social impact evaluations within projects, McLoughlin et al (2009:157) have proposed the five step SIMPLE approach to impact measurement in SEs which they call SCOPE IT; MAP IT; TRACK IT; TELL IT; EMBED IT. According to the authors, this five step approach is aimed to support SE manage to design evaluations, engage internal and external stakeholders, monitor and control activities, evaluate the results and then incorporate the results to inform future 'improved 
operation performance, planning and strategic decision making'. As a holistic evaluation method, the SIMPLE model is designed as a comprehensive evaluation tool that simultaneously functions as a diagnostic, programmatic, planning and training mechanism. The authors therefore claim that the SIMPLE method of evaluation is both a social impact consultancy tool as well as an impact training programme (McLoughlin et al, 2009:174). Consequently they contend that by going through the SIMPLE five stage process, users will develop the skills set for impact evaluation that is required to sustain continuous improvement and informed managerial decisions for SEs.

An overview of the five stages of the SIMPLE method provides a useful guide to the main principles of performance measurement for the holistic evaluation process to be conducted. In Stage 1 - SCOPE IT - the task for the SE is to clearly set out the mission statement and the social issues that will be the focus of the intervention. It is at this stage that the proposed impact should be defined and the indicators to measure these impacts should be identified. It is also at this phase that a clear differentiation between outcomes and impacts must be demarcated so as to avoid confusion in assessing the results. According to Liket et al (2014), evaluation failures tend to reflect the problem of clearly separating indicators that should be measured at the outcome level as discrete from those at the impact level. For example, a CBTE of a rural women cooperative of agro processors with a mission statement to reduce poverty and increase income generation among members, may propose that the outcome indicator should be the involvement of members in the project for at least twenty hours of paid employment per week. In this regard, the causal link between the activities, input and outcome could be directly mapped from the inception to the completion of the project. The paid employment hours that were generated would be attributed only the project and show that this income generation would also not have been available to the women apart from the intervention. At the impact level, the effectiveness of the programme would be evaluated based on of the mission statement's goal of improved livelihoods which would be measured of terms of public good indicators such as increased multiplier spend in the local community due to the extra income earned from the cooperative, improved nutrition and health among the children of the beneficiaries and also enhanced well-being and confidence among the women.

At Stages 2 and 3, the MAP IT and TRACK IT steps focus on the measurement of the evaluation process. Here performance management involves the triple bottom line (3BL) that includes the assessment of conventional financial accounting as well as the social and environmental impacts to extend to the quadruple bottom line (4BL); that further takes into account GDP growth, financial sustainability and benefits saved by the community (McLoughlin et al, 2001:166). It is at this stage that the logic model discussed earlier in this chapter of Activities, Outputs, Outcomes and Impacts are operationalized with the aim to demonstrate the causal chain linking the work undertaken and the proposed results. For Stage 4 - the TELL IT step focuses on reporting the data in order to make the case of the effectiveness of the SE utilizing comparative data, benchmarking and base line data that demonstrates the improvements that have occurred and the benefits achieved. In this regard, the SIMPLE model assumes a training dimension in equipping managers to apply the method to manage the data. This skills training component extends to Stage 5 - EMBED IT where 
the learning produced from the evaluation process is integrated into operational change management programmes for the SE to adopt. The SIMPLE model is similar to SROI as they both represent hybrid evaluation approaches to account for social outcomes and they are situated mainly within the positivist tradition of evaluation that aim to produce objective and measurable knowledge of the performance and costs of projects and organizations.

Yet even among the proponents of positivist evaluation methods, there is some recognition of the limitations of these methods by themselves in capturing all the intangible social impacts of interventions. While maintaining that positivist methodologies should be scaled up in the evaluation of development projects, White (2009) acknowledges that it is also important to incorporate qualitative methods such as focus groups, semi-structured interviews and ethnography and anthropology in evaluation exercises. He argues that by employing a mixed methods approach, the overall evaluation is improved as this will enable quantitative work to be guided by 'qualitative insight'. The importance of fieldwork in such instances are considered helpful to contextualize the findings, so that answers are not only provided as to whether the intervention worked, but also explains why it may have done so. But for White (2009), stakeholder views and appropriation of local knowledge are still secondary and mainly serves to supplement and provide an explanatory framework for the patterns that emerge from the data.

Fourth generation evaluation methods (FGE) Some evaluation researchers advocate that collaboration among stakeholders are pre-requisite for the evaluation process to be utilized in such a way as to contribute to organizational learning and improved decision-making by SE managers. This is referred to as utilization-focused evaluation which asserts that the end use of evaluation determines the overall value of the exercise and as such has some pedagogical purpose (Liket et al, 2014). According to Liket et al, (2014:173), the focus on collaboration represents a 'constructivist view of evaluation knowledge' that proposes a participatory approach which is termed fourth generation evaluation methods (FGE). They maintain that through participatory engagement, the quality of the evaluation is improved as stakeholders are afforded greater control and involvement in the process and so are better positioned to engage in continuous improvement. In the constructivist viewpoint the notion of rigor is replaced by the pursuit of engaging the stakeholders in the facilitation process as enablers and agents of change by harnessing their 'critical and elusive' knowledge on the operations and the outcomes of the project (Hall \& Arvidson, 2014). The operationalization of the participatory evaluation process is therefore deemed to be more democratic and open, that allows for the inclusion of an eclectic range of methods to be selected in accordance to the contextual needs of the project, rather than on 'predetermined metrics and measures of success' (Chouinard, 2013).

\section{Participatory Evaluation (PE) and Empowerment Evaluation (EE) Participatory} approaches to evaluation attempt to privilege the voices of participants and beneficiaries in the assessment of the outcomes of the intervention. Based on the philosophical principles of constructivism, participatory and empowerment evaluation models view outcomes as flexible, critical and situated since they are mainly identified and defined by the users and beneficiaries themselves rather than the evaluator. Accordingly, the focus is on the 
participants who are best able to identify their needs and whose insights are invaluable in defining the problem, in designing the intervention and also ascertaining whether the outcomes are successful (Chambers, 2009; Hall \& Arvidson, 2014; Nichols, 2002). In the case of marginalized groups and the disempowered, participatory action research activities offer them the opportunity to gain more control of their lives and to empower them to be actively involved in enacting and sustaining the change that is required to improve their standard of living. Both participatory evaluation (PE) and empowerment evaluation (EE) share the same commitment to societal change and capacity building. For EE however, the emphasis is on achieving goals of social justice for 'disenfranchised minority groups', while practical PE is defined by the involvement of stakeholders in a partnership with facilitators in the design of the evaluation and who then ultimately share the responsibility for the development of the evaluation report (Smits \& Champagne, 2008b). Rather than project managers having to be only accountable to the funders and those who hold the purse strings, with participatory evaluation, the beneficiaries are afforded the ownership as the persons to whom the SE managers are really accountable to in the overall evaluation process.

At the theoretical level, EE and PE propose that in the collaboration of participants and evaluators, there is the co-creation of new knowledge that encourages the instrumental use of the findings and results which in turn becomes 'actionable knowledge' that addresses the problem that was the focus of the intervention (Smits \& Champagne, 2008b). Within the developmental context, PP and EE have been preferred as they seem to shift the preoccupation with measuring impacts to the notion of managing for sustained impacts that lead to real societal change (Ofir, 2013). As alternatives to the positivist evaluation methodologies, participatory evaluation claims to engage in evaluation for development rather than merely only assessing the characteristics of the developmental process. With the emphasis of participatory methods on capacity building, co-creation of knowledge and organizational learning, there is the opportunity to relate these outcomes to specific change programmes and activities on the ground that provide some evidence of the pragmatic legitimacy of the intervention. By applying the evaluation process as a mechanism for development, participatory methods appear to much more equipped to tackle poverty reduction, income generation and unemployment which are indicators of social impacts. The evidence of success of participatory models are therefore demonstrated in change of behavior and attitudes where individuals or small community groups are empowered to act to compete for resources, influence policy making and are networked to others outside their groups to access resources and engage in productive exercises where previously this was not the case(Miller \& Campbell, 2006b).

Among social services and rehabilitative health programmes, participatory evaluation methods have been widely advocated as they provide the means for participants to be involved in the design of the change programme and to monitor and self-assess the recovery journey in the overall strategy for personal change. An example of this PE method is the Outcomes Star (OS) model that has been developed as a tool to assess the effectiveness of reform and rehabilitation programmes targeting a range of social issues such as homelessness, mental health and drug recovery. According to Hall \& Arvidson (2014) as it has been developed as a holistic model to be integrated into the working activities of the organization, the OS model is operationalized as a service rather than a separate evaluation 
exercise. The aim of the OS model is to not only to measure the outcomes of the interventions, but to also provide guidance in achieving the desired outcomes. In its application, the OS model is based on a scale of expected behavior represented as a star that maps out a model of change indicating the steps that are to be undertaken gain the desired outcomes are that the users are hoping to achieve. In an overall interactive process, the user is encouraged to reflect on past actions and in the process make determinations on the relationship between behavior and outcomes. In this way, the user owns the evaluation process and is enabled to assess and then to make decisions on future pathways for change. But the activity of self-assessment that involves subjective judgments and feelings of the users poses problems of the accuracy or reliability of these accounts. Self-reporting methods have shown that participants may not be totally truthful in these exercises and tend to present positive reports and give information that they think the evaluator would like to hear (Hall \& Arvidson, 2014:149). In such instances, it is difficult to control for bias and the trust between users and the facilitator may be broken down if there is requirement to provide verification such as mandatory blood tests as for example in the case of a drug reform programme (White, 2013). An important caveat here is that even though the underlying tenets of participatory evaluation do not focus on being objective and value free, they still adhere to the fundamental principles of being evidence based. This means that constructivist knowledge production are also expected to be verifiable and based on empirical data gathering and analysis that clarifies the outcomes and impacts of interventions.

The extent to which participatory evaluation methods have been able to provide the empirical evidence to support the claims of empowerment and social impacts have been a major contention. The lack of case study evidence, unanimity in practice as well as the fact that both PE and EE bear similar attributes to general change and social justice theories; all contribute to the blurring of the distinctive contribution of participatory evaluation in theory and practice. The theoretical gaps emerge at moments of operationalization of the participatory methods in terms of clearly defining the context where such methods are suitable and the exact role of the evaluator in facilitating the transfer of power to participants in the evaluation process (Miller \& Campbell, 2006b). The major risk to participatory evaluation methods is that they may become so normalized that they function more as a rhetorical set piece for development interventions that function essentially as an ideal type rather than a practical programme of change.

The key, defining purpose of participatory development is the engagement of a bottom-up process that enables participants to build skills and competencies that allow for recognition and access to productive resources as well as to influence policymaking and governance. Therefore there is a need for participatory methods to interrogate the context of the parameters of social change in terms of the realities of the external environment where these interventions are situated. While PE and EE activities may educate, equip and train individuals and small community groups; the possibilities to enact change will still depend on the external regulatory and political framework. Societal change involves the negotiation of power between those who are in control and those who wish to gain control. Development is not solely a function of the enhancement of the skills sets and market potential of marginalized groups, but also requires external validation and support. As (Scarlato, 2013) contends, the participatory activities of social projects in many developing nations have yet to 
address 'the mechanism through which poverty persists that are embedded in and reproduced by social relations inside specific groups and territories'. Undoubtedly, participatory evaluation methods provide some space for marginalized groups to tackle the problem of social exclusion and to be more proactive agents of change, but it should be also acknowledged that the predominant determinants of change are still measured by principles of new performance management characterized by principles of accountability based on economic efficiency and effectiveness (Chouinard, 2013); White, 2009). As such, the next generation of participatory evaluation methods must move towards an engagement in an agenda of social mobilization in order to attain the credence and persuasive power to actualize claims of 'societal change'.

\subsubsection{Social enterprise evaluation in the tourism sector}

Within the tourism sector, the principles of social entrepreneurship and enterprise have been mainly applied in initiatives harnessing the considerable economic prowess of tourism for poverty alleviation. The Pro Poor Tourism (PPT) agenda makes the case for involving profitable companies in the industry in engaging in projects that reduce the marginalization of the poor and investing in local community based tourism initiatives (Scheyvens \& Russell, 2012). However, there are some risks of such PPT activities in becoming mainly Corporate Social Responsibility (CSR) programmes to enhance the image and goodwill of large corporations, which while providing some improvement in social welfare and local livelihoods, may not really shift the power balance towards greater economic independence for beneficiaries (Ashley \& Haysom, 2006). Alternative models of tourism development have also viewed social enterprise models as a means of facilitating indigenous ownership and economic empowerment of locals.

In a critique of modernization imperatives of large-scale, transnational, top-down tourism planning and development policies, community based tourism enterprises (CBTEs) have been widely advocated as a means of ensuring and enhancing economic, social and environmental sustainability (Panagiotopoulou \& Stratigea, 2014; Zapata, Hall, Lindo, \& Vanderschaeghe, 2011). In this regard, participatory approaches characterised by principles of bottom-up planning, networking and multi-stakeholder engagement, and capacity building to facilitate decision making and grassroots mobilisation have been featured in policy planning and activities aimed at stimulating positive social, economic and environmental wellbeing in marginalised communities. Given the claims of the efficacy of social enterprise tourism projects as a path toward empowerment for local communities, there is an even greater mandate for more focus on the benefits of the integration of evaluation processes in their design and operations in order to achieve overall developmental goals (Ofir, 2013). However with the critical turn in tourism studies leading to the currency and prominence of tourism as a developmental tool and agent for social change, there is a concomitant imperative to interrogate the key arguments and implications of PE and EE methods in CBTEs and PPT projects (McGehee, Kline, \& Knollenberg, 2014; Panagiotopoulou \& Stratigea, 2014; Papineau \& Kiely, 1996).

As an area of research, there is considerable empirical void in the extant literature on evaluation processes and implementation within social enterprises in the tourism sector. 
There are some indications however that traditional evaluation methods based on objective measurements of outcomes may be more the norm than participatory approaches. In a study on the success factors of social enterprises in tourism, von der Weppen \& Cochrane ( 2012) observed that the performance management practices of tourism enterprises tended to pursue normative approaches of evaluation 'involving a mix of indicators and methods designed to chart progress against mission aims and outcomes'. They also found that the measurement of impacts by tourism enterprises was for the most part conducted informally and irregularly. It was also noted that the evaluation procedures were usually sidelined in routine work practices.

According to Scheyvens \& Russell (2012), it is difficult to measure and quantify the net benefits of tourism to a community due to the considerable resources required to conduct the systematic and comparative assessments required for such evaluations. Traditional econometric models such as the tourism multiplier, input output models, cost benefit analysis and other variants that attempt to measure economic impacts when applied in the context of marginalized or remote community groups are often hindered by limited availability and inconsistent and poor financial data that undermine the validity of these methods (Zapata et al, 2011:736). Furthermore, these socio-economic models are similarly deficient as other mainstream evaluation models in producing the knowledge that values the perspectives of stakeholders. But while there are theoretical models that may explain the social impacts of tourism such as Doxey's Irridix for example, they are not applicable as evaluative tools that may be used to assess the social impacts of CBTEs. According to Panagiotopoulou \& Stratigea (2014), most of the research of the social impacts of CBTE are mainly based on case study analysis and traditional qualitative methods of interviews and focus groups which are the more popular methods used to assess the social impacts of development projects (Scheyvens \& Russell, 2012). Generally, there is a lack of a focal theory or framework that has been developed that attests to specific variables that should be incorporated in the evaluation of the social impacts of CBTEs.

In a study on CBTEs in Nicaragua conducted by Zapata et al (2011), focus groups were undertaken across 34 CBTEs to garner participants' views on the impacts of the tourism projects to the community. The main indicators that were identified to measure the impacts of the CBTEs were employment and income, skills and self-esteem, women, family the community and the environment. The findings of the study show that participants held the view that CBTEs provided marginal financial benefits to the local economy and that their profitability were low. According to Zapata et al (2011) this perception of the economic performance by CBTEs members under-estimated the contribution of the organizations as they were based on accounting protocols that did not capture the value-added benefits that the operations of the CBTEs made to the agricultural and other productive sectors of the community (Zapata et al, 2011:736). So evidence of economic benefits of the CBTEs in reducing financial risks by the reduction of dependency on agriculture and the economic diversification of the local economy through CBTE activities were not fully accounted for in their assessments. This suggests that there is need for participatory evaluation methods to cover training in the appraisal of the economic contribution of CBTEs activities to local livelihoods in order to encourage and sustain these projects over the long term. By contrast however, in their evaluation of the benefits gained from the projects in terms of skills and 
self-esteem, there was considerable affirmation of positive outcomes. CBTE members reported the acquisition of education and training that included tourism related management as well as business and social skills. It is therefore apparent that participatory, bottom-up activities are more likely to be effective in transferring the skills and competencies to empower users to acquire social capital to gain access to productive market and value chain networks.

In terms of the evaluation of the impacts of CBTEs at the community level, the study by Zapata et al (2011) showed that some proportion of profits were re-invested in the local community. Indirectly, these benefits were demonstrated in the improvement in local infrastructure of public areas such as 'water supply, the cleaning of public areas, paths and gardens (739). This in turn raised the profile of these communities that positioned them to attract external investment that expanded opportunities to link to local markets and other tourism entrepreneurs in the accommodation and attraction sectors. According to McGehee et al., (2014), this type of community participation reflects a high level of self-efficacy which is associated with awareness, participation and support for social issues embodied in social movement theory. This provides the opportunity for the marginalized and excluded to 'implement social change in ways that maximize their limited power and resources'. In relation to $\mathrm{PE}$ and $\mathrm{EE}$, it is therefore important to recognize McGhee's claim of the pivotal role of social movement theory to inform practice and to provide the framework to assess and support 'grassroots-level sustainable tourism development' (143). In order to move forward from the traditional remit of the amelioration of social exclusion, participatory evaluation may also need to focus on activities involving conscious-raising, network development, selfdetermination, confidence and collaboration that are key features and outcomes of social movement theory. In so doing CBTEs will be more likely to create opportunities to contribute to social outcomes of poverty alleviation and longer term impacts of positive societal change.

\subsubsection{Exploring the gender dimension}

The specific needs of women have been focal to development projects in recognition that they are usually disproportionately hindered by poverty. Moreover, studies have also shown that with the increase of the income of women there are substantial improvements in the standard of living, livelihoods and wellbeing of children and communities on a whole (Fotheringham \& Saunders, 2014); (Nielsen \& Samia, 2008; Zapata et al., 2011). Women have been a popular target group for social enterprise projects and intervention and in spite of an overall paucity of research that specifically clarifies the role of social enterprise in poverty reduction, there are some findings that indicate that SE have been beneficial in providing for women 'increased income, development of skills, improved social and business networks, increased confidence and greater respect and acceptance from families' (Fotheringham \& Saunders, 2014). Participatory methodologies also provide the framework to craft interventions that are relevant and distinctly address the unique needs of women particularly in situations where they are marginalized and disempowered. In this regard, PE and EE are critical tools in creating an enabling environment to that will support them in their traditional roles of caring for the children and family but at the same do not limit them only to these activities. 
Critically, participatory evaluation methods should also provide the context for women to have a voice in identifying their needs and to develop the skills to reflect on, to analyze and make decisions regarding their livelihoods. McGehee et al (2014:144) report on a study among Afghani women that found that those who were aware of their potential and abilities tended to actively engage in community actions and get involved in productive enterprise. Within the tourism sector there has been a longstanding recognition that tourism offers women an 'avenue for activism and leadership in community and political life and provides vital employment and entrepreneurial opportunities' (Figueroa-Domecq, Pritchard, Segovia-Pérez, Morgan, \& Villacé-Molinero, 2015). Female entrepreneurs have also been recognized for their leadership and success in social enterprise businesses in tourism. In a study of female entrepreneurs in tourism in Uganda it was found that $80 \%$ of those sampled were running their businesses for over 10 years thereby indicating their ability to successfully operate and sustain their business over the long term (Katongole, Ahebwa, \& Kawere, 2013). This suggests that there have been significant beneficial outcomes that have been gained in specifically targeting women in the developmental agenda of participatory evaluation praxis in social enterprise agencies and interventions.

\subsubsection{Conclusion}

Much of the literature and work on participatory research have tended to focus on participatory practice in terms of implementation rather than on the evaluation of the participatory process. However, an inherent feature of participatory methods is that they should bring all participants 'together to problem solve and produce new knowledge in an ongoing learning and reflective process' (Blackstock, Kelly, \& Horsey, 2006; Miyoshi, 2013). This suggests that participatory research should entail some space for assessment in order to clearly identify areas that could have been improved, what could have been done differently or even more critically interrogating the assumptions and claims of the methodology (Miller \& Campbell, 2006b). In other words the question should not only 'be why does this not work', but also 'why we are doing what we are doing'? Some have argued that evaluation of participatory research should also examine issues of power in critiquing 'what works for whom and whose interests are being served' in the ex post or final evaluations (Kindon, Pain, \& Kesby, 2007).

The discussion in this chapter has shown that conventional approaches to evaluation have tended to centre on measuring the extent to which the intended results have been achieved in line with the project's overall objective. Generally development interventions usually include activities such as reviews, supervision missions, and assessments. This is seen as part of the monitoring and evaluation process in order to manage the likely 'drift' between project objectives and the actual implementation of the project. For the most part, performance management has been defined by financial reporting and the quest for objective assessments. However, it has been argued that it is important to include the experiences and perceptions of participants in the evaluation process so that that 'the voices of those most affected by the project may be counted (Chambers, 2009). As a leading advocate of participatory development, Chambers contends that those who live in poverty, who are vulnerable and marginalised are the best judges and prime authorities on their lives and 
livelihoods and how they are affected'. In this regard participatory research and evaluation engages the viewpoints and responses of the community in order to determine the consensus of opinion on the impacts of the project. However, there are some limitations to the implementation of participatory evaluation methods particularly in terms of operationalization and addressing issues of redistributive justice and power on behalf of beneficiaries. Social enterprises in tourism that embrace the values of empowerment and development in their mission statements and activities, may therefore have to pay more earnest attention in interrogating the extent to which integrating participatory evaluation principles and praxis in their operations support of the quest to achieve sustainable, beneficial societal change.

While the discussion of participatory evaluation methods in this chapter have mostly highlighted case study examples from the developing world, social problems of disempowerment and inequalities of wealth distribution, uneven development in lagging rural regions are also features of wealthier, developed economies. These methods therefore have global application in addressing problems of social exclusion and poverty by providing the framework for capacity building and human development. As key change agents that seek to redress and provide solutions to social problems, SEs in both the developed and the developing world have been the loci of extensive participatory evaluation methodologies, and have produced much of the knowledge that informs current praxis. As such their operations are pivotal in contributing to understandings of how and why they work. The growth of social enterprise activity in tourism particularly in the field of development and pro poor tourism initiatives have put the spotlight on their effectiveness and as this chapter has shown, greater scrutiny of the tools and methods that purport to measure and evaluate social impacts. But there is yet much more research to be conducted among CBTEs as well as at the macro, large scale level of tourism operations to refine the tools and modalities that are employed in the evaluation of social impacts. Evaluation methodologies and research are still considered to be an emergent yet promising field. Accordingly, as a research domain, it must be dynamic and innovative to respond to, and remain relevant to the complex, ever rapidly changing social interactions and evolutionary currents in today's world. 


\section{References}

Ashley, C., \& Haysom, G. (2006). From philanthropy to a different way of doing business: Strategies and challenges in integrating pro-poor approaches into tourism business. Development Southern Africa, 23(2), 265-280. doi:10.1080/03768350600707553

Bagnoli, L., \& Megali, C. (2011). Measuring performance in social enterprises. Nonprofit and Voluntary Sector Quarterly, 40(1), 149-165. doi:10.1177/0899764009351111

Behn, R. D. (2003). Why measure performance? different purposes require different measures. Public Administration Review, 63, 586-5860606.

Blackstock, K. L., Kelly, G. J., \& Horsey, B. L. (2006). Developing and applying a framework to evaluate participatory research for sustainability. Ecological Economics, 60, 726-742; 726. doi:10.1016/j.ecolecon.2006.05.014

Chambers, R. (2009). So that the poor counts more: Using participatory methods for impact evaluation. Institute of Development Effectiveness, 1(3), 243-246.

Chouinard, J. A. (2013). The case for participatory evaluation in an era of accountability. American Journal of Evaluation, 34(2), 237-253. doi:10.1177/1098214013478142

Figueroa-Domecq, C., Pritchard, A., Segovia-Pérez, M., Morgan, N., \& Villacé-Molinero, T. (2015). Tourism gender research: A critical accounting. Annals of Tourism Research, 52, 87-103. doi:http://dx.doi.org/10.1016/j.annals.2015.02.001 
Fotheringham, S., \& Saunders, C. (2014). Social enterprise as poverty reducing strategy for women. Social Enterprise Journal, 10(3), 176-199. doi:10.1108/SEJ-06-2013-0028

Hadad, S., \& Gauca, O. (. (2014). Social impact measurement in social entrepreneurial organizations. Management \& Marketing, 9(2), 119-136.

Hall, K., \& Arvidson, M. (2014). How do we know if social enterprise works? tools for assessing social enterprise performance. In S. Denny, \& F. Seddon (Eds.), Social enterprise: Accountability and evaluation around the world (pp. 141-141-157). London and New York: Routledge Taylor \& Francis.

Katongole, C., Ahebwa, W. M., \& Kawere, R. (2013). Enterprise success and entrepreneur's personality traits: An analysis of micro- and small-scale women-owned enterprises in uganda's tourism industry. Tourism and Hospitality Research, 13(3), 166-177. doi:10.1177/1467358414524979

Kindon, S., Pain, R., \& Kesby, M. (Eds.). (2007). Participatory action research approaches and methods connecting people, participation and place. London and New York: Routledge.

Liket, K. C., Rey-Garcia, M., \& Maas, K. E. H. (2014). Why aren't evaluations working and what to do about it: A framework for negotiating meaningful evaluation in nonprofits. American Journal of Evaluation, 35(2), 171-188. doi:10.1177/1098214013517736

McGehee, N. G., Kline, C., \& Knollenberg, W. (2014). Social movements and tourism-related local action. Annals of Tourism Research, 48, 140-155.

doi:http://dx.doi.org/10.1016/j.annals.2014.06.004 
McLoughlin, J., Kaminski, J., Sodagar, B., Khan, S., Harris, R., Arnaudo, G., \& Sinéad Mc Brearty. (2009). A strategic approach to social impact measurement of social enterprises. Social Enterprise Journal, 5(2), 154-178. doi:http://dx.doi.org/10.1108/17508610910981734

Miller, R. L., \& Campbell, R. (2006a). Taking stock of empowerment evaluation: An empirical review. American Journal of Evaluation, 27(3), 296-319. doi:10.1177/109821400602700303

Miller, R. L., \& Campbell, R. (2006b). Taking stock of empowerment evaluation: An empirical review. American Journal of Evaluation, 27(3), 296-319. doi:10.1177/109821400602700303

Miyoshi, K. (2013). Toward a more holistic evaluation approach for rural development. American Journal of Evaluation, 34(4), 587-589. doi:10.1177/1098214013493494

Nichols, L. (2002). Participatory program planning: Including program participants and evaluators. Evaluation and Program Planning, 25(1), 1-14. doi:http://dx.doi.org/10.1016/S01497189(01)00044-1

Nielsen, C., \& Samia, P. (2008). Understanding key factors in social enterprise development of the BOP: A systems approach applied to case studies in the philippines. Journal of Consumer Marketing, 25(7), 446-454.

Ofir, Z. (2013). Strengthening evaluation for development. American Journal of Evaluation, 34(4), 582-586. doi:10.1177/1098214013497531

Panagiotopoulou, M., \& Stratigea, A. (2014). A participatory methodological framework for paving alternative local tourist development paths-the case of Sterea Ellada region. European Journal of Futures Research, 2(1), 1-15. doi:10.1007/s40309-014-0044-7 
Papineau, D., \& Kiely, M. C. (1996). Participatory evaluation in a community organization: Fostering stakeholder empowerment and utilization. Evaluation and Program Planning, 19(1), 79-93. doi:http://dx.doi.org/10.1016/0149-7189(95)00041-0

Parenson, T. (2011). The criteria for a solid impact evaluation in social entreprenuership. Society and Business Review, 6(1), 39-39-48.

Pathak, P., \& Dattani, P. (2014). Social return on investment: Three technical challenges. Social Enterprise Journal, 10(2), 91-104. doi:10.1108/SEJ-06-2012-0019

Paton, R. (2003). Managing and measuring social enterprises. London: Sage Publications.

Scarlato, M. (2013). Social enterprise, capabilities and development paradigms: Lessons from Ecuador. The Journal of Development Studies, 49(9), 1270-1283.

doi:10.1080/00220388.2013.790962

Scheyvens, R., \& Russell, M. (2012). Tourism and poverty alleviation in Fiji: Comparing the impacts of small- and large-scale tourism enterprises. Journal of Sustainable Tourism, 20(3), 417-436. doi:10.1080/09669582.2011.629049

Smits, P. A., \& Champagne, F. (2008a). An assessment of the theoretical underpinnings of practical participatory evaluation. American Journal of Evaluation, 29(4), 427-442. doi:10.1177/1098214008325023

Smits, P. A., \& Champagne, F. (2008b). An assessment of the theoretical underpinnings of practical participatory evaluation. American Journal of Evaluation, 29(4), 427-442. doi:10.1177/1098214008325023 
von, der Weppen., \& Cochrane, J. (2012). Social enterprises in tourism: An exploratory study of operational models and success factors. Journal of Sustainable Tourism, 20(3), 497-511. doi:10.1080/09669582.2012.663377

Zapata, M. J., Hall, C. M., Lindo, P., \& Vanderschaeghe, M. (2011). Can community-based tourism contribute to development and poverty alleviation? Lessons from Nicaragua. Current Issues in Tourism, 14(8), 725-749. doi:10.1080/13683500.2011.559200 